\title{
BMJ Open Which public health interventions are effective in reducing morbidity, mortality and health inequalities from infectious diseases amongst children in low-income and middle-income countries (LMICs): protocol for an umbrella review
}

\author{
Elodie Besnier (D) , ${ }^{1}$ Katie Thomson (D) , ${ }^{2}$ Donata Stonkute, ${ }^{3}$ Talal Mohammad, ${ }^{3}$ \\ Nasima Akhter (1) , ${ }^{4}$ Adam Todd (i) , ${ }^{5}$ Magnus Rom Jensen (i) , ${ }^{6}$ Astrid Kilvik, ${ }^{7}$ \\ Clare Bambra (10 ${ }^{8}$
}

To cite: Besnier E, Thomson $\mathrm{K}$ Stonkute D, et al. Which public health interventions are effective in reducing morbidity, mortality and health inequalities from infectious diseases amongst children in low-income and middle-income countries (LMICs): protocol for an umbrella review. BMJ Open 2019;9:e032981. doi:10.1136/ bmjopen-2019-032981

- Prepublication history and additional material for this paper are available online. To view these files, please visit the journal online (http://dx.doi. org/10.1136/bmjopen-2019032981).

Received 15 July 2019 Revised 30 0ctober 2019 Accepted 19 November 2019

Check for updates

(c) Author(s) (or their employer(s)) 2019. Re-use permitted under CC BY-NC. No commercial re-use. See rights and permissions. Published by BMJ.

For numbered affiliations see end of article.

Correspondence to

Elodie Besnier;

elodie.besnier@ntnu.no

\section{ABSTRACTS}

Introduction Despite significant progress in the last few decades, infectious diseases remain a significant threat to children's health in low-income and middle-income countries. Effective means of prevention and control for these diseases exist, making any differences in the burden of these diseases between population groups or countries inequitable. Yet, gaps remain in our knowledge of the effect these public health interventions have on health inequalities in children, especially in low-income and middle-income countries. This umbrella review aims to address some of these gaps by exploring which public health interventions are effective in reducing morbidity, mortality and health inequalities from infectious diseases among children in low-income and middle-income countries.

Methods and analysis An umbrella review will be conducted to identify systematic reviews or evidence synthesis of public health interventions that reduce morbidity, mortality and/or health inequalities due to infectious diseases among children (aged under 5 years) in low-income and middle-income countries. The interventions of interest are public health interventions targeting infectious diseases or associated risk factors in children. We will search for reviews reporting health and health inequalities outcomes in and between populations. The literature search will be undertaken using the Cochrane Library, Medline, EMBASE, the CAB Global Health database, Health Evidence, the Campbell Collaboration Library of Systematic Reviews, International Initiative for Impact Evaluation Systematic review repository, Scopus, the Social Sciences Citation Index and PROSPERO.

Additionally, a manual search will be performed in Google Scholar and three international organisations websites (UNICEF Office of Research-Innocenti, UNICEF, WHO) to capture grey literature. Data from the records meeting our inclusion/exclusion criteria will be collated using a narrative synthesis approach.

\section{Strengths and limitations of this study}

- This umbrella review will help to assess the availability and quality of evidence on the population health and equity effect of selected public health interventions addressing the burden of infectious diseases in children in low-income and middle-income countries.

- By searching for a wide range of public health interventions, this review will help identify areas or sectors where the evidence on equity is weak and needs further research.

- Including both academic and grey literature as well as different approaches and definition of equity will help overcome some of the difficulties faced in previous mapping of the literature on this topic.

- More recent primary studies on new interventions may not be captured, as they may not have been synthesised into reviews yet.

- The variety of interventions covered constrains the type of synthesis and analysis possible with the data extracted, hence our decision to opt for a narrative synthesis rather than a quantitative analysis.

Ethics and dissemination This review will exclusively work with anonymous group-level information available from published reviews. No ethical approval was required.

The results of the review will be submitted for publication in academic journals and presented at international public health conferences. Additionally, key findings will be summarised for dissemination to a wider policy and general public audience as part of the Centre for Global Health Inequalities Research's policy work.

PROSPERO registration number CRD42019141673 


\section{INTRODUCTION}

Despite economic development and improvement of morbidity and mortality globally, disparities in health have persisted between and within countries. ${ }^{1-4}$ As children depend on others for their health and well-being, they are particularly affected by these inequalities. ${ }^{5}$ For example, in 2016, the mortality rate for children under 5 years old ranged from 2.2 per 1000 live births in Luxembourg to 130.6 in the Central African Republic, with two regions-South Asia and western sub-Saharan Africaaccounting for more than half of all under 5 deaths globally. ${ }^{2}$ The Institute for Health Metrics and Evaluation Global Burden of Diseases estimates that while under 5 mortality represented less than $10 \%$ of all deaths globally in 2017, they made up more than one-third of all deaths in low-income countries. ${ }^{6}$ Additionally, according to the United Nations Children's Fund (UNICEF), in countries with high child mortality, the children living in the poorest households are almost twice as likely to die before the age of 5 years than those from the richest households. ${ }^{3}$

Some major progress has been made in fighting infectious diseases. ${ }^{7}$ The number of deaths attributed to these diseases has decreased in the last few decades, ${ }^{8}$ while the incidence of major infectious threats to global health, such as HIV, tuberculosis and malaria have dropped significantly since $2000 .{ }^{9}$ According to UNICEF, about $70 \%$ of the global decline in children under 5 mortality since 2000 is due to the prevention and treatment of infectious diseases. ${ }^{3}$ However, the burden in this age group remains significant, especially in low-income and middle-income countries (LMICs). Lower respiratory infections, such as pneumonia, were among the top three causes of death in children under 5 years in both LMICs while diseases like whooping cough and measles ranked within the 10 th leading causes of death. ${ }^{10}$ In 2016, the leading causes of deaths globally in infants and young children (as percentages of all deaths in that age group) were three infectious diseases: acute respiratory infections, diarrhoea and malaria. ${ }^{11}$ These diseases were also three of the five leading causes of disability-adjusted life years-a measure of years in good health lost due to illness or premature death-in children under 5 living in low-income countries in $2017 .^{10}$

Effective means of prevention and control for these diseases, such as immunisation or vector control, are available. For example, WHO has licensed vaccines for the prevention and control of 25 infections, ${ }^{12} 11$ of which are recommended for all children worldwide. ${ }^{13}$ Some health promoting interventions, such as health education or improved infant and child nutrition, have also a protective effect against some of these diseases. ${ }^{1415}$ Therefore, any inequalities in the burden of these diseases between population groups or countries could be defined as avoidable, thus qualifying as inequities according to WHO definition: 'avoidable inequalities in health between groups of people within countries and between countries [arising] from inequalities within and between societies'. ${ }^{16}$
Globally, the evidence base on the effect of public health interventions on health inequalities in children is growing but gaps remain. ${ }^{15} 1718$ Previous work has suggested that the available evidence is disproportionally coming from high-income countries. ${ }^{17}{ }^{19}$ A 2018 mapping of the evidence available on LMICs regarding interventions to improve child well-being, ${ }^{21}{ }^{22}$ also found that while reviews may provide data disaggregated by population group, very few explicitly focus on the potential equity issues raised by the differences between groups. Finally, most of the reviews available focus exclusively on targeted interventions towards disadvantaged groups without necessarily addressing the gap between or across different groups. ${ }^{1723}$ Therefore, the impact of such interventions may not be reflected across or between different population groups.

In this umbrella review, we explore which public health interventions are effective in reducing morbidity, mortality and health inequalities from infectious diseases among children in LMICs.

\section{METHODS AND ANALYSIS}

An umbrella review will be conducted to identify systematic reviews or evidence synthesis of public health interventions that reduce morbidity, mortality and/or health inequalities due to infectious diseases among children (aged under 5 years) in LMICs. An umbrella review is defined as the compilation and synthesis of evidence from multiple (systematic) reviews into a single, easyto-use document. ${ }^{24}$ Umbrella reviews, also called 'overview of reviews' or 'review of reviews', are an established method of locating, appraising and synthesising systematic reviews of interventions. ${ }^{25}$ They use systematic review methodology to locate and evaluate published systematic reviews of interventions: a systematic search of the literature, a screening and selection of the records according to predefined criteria, systematic data extraction and quality appraisal, and synthesis of the results or findings. The main difference with conventional reviews is the type of publication included, as umbrella reviews include other systematic reviews or evidence synthesis rather than primary studies. Umbrella reviews are, therefore, able to present the overarching findings of such systematic reviews (usually considered to be the highest level of evidence) and can also extract data from the best quality studies within them. ${ }^{26}$ In this way, they represent an effective way of rapidly reviewing a broad evidence base. Umbrella review methodology is an increasingly commonly used technique in public health and medical research $^{20} 27-30$ but no umbrella review has yet been conducted in relation to reducing morbidity, mortality and health inequalities from infectious diseases among children.

This umbrella review focuses on infectious or communicable diseases as defined in the 11th International Classification of Diseases: 'conditions caused by a pathogenic organism or microorganism, such as a bacterium, virus, 
parasite or fungus'. ${ }^{31}$ These diseases can be transmitted from person to person or from animals to people either directly or indirectly. For the purpose of this review and given their significant burden in LMICs, only the burden of these diseases in children will be considered.

\section{Model, framework or theory}

This review builds on the concept of population health as defined by the Canadian Institute for Advanced Research, which involves maximising health at population level while reducing inequities by addressing the determinants of health. ${ }^{32}$ Under this conception of health, public health is to be understood as the science and process to improve and ensure the health of and across populations. Therefore, in this review, public health interventions will be defined as policies, programmes or actions aiming at 'preventing disease, prolonging life and promoting health through the organised efforts of society' ${ }^{33}$ and 'shift(ing) the distribution of health risk by addressing the underlying social, economic and environmental conditions'. ${ }^{34}$

In terms of interventions to reduce health inequalities, it builds on the Bambra et al framework. ${ }^{35}$ Drawing on the health inequalities conceptual literature ${ }^{36}{ }^{37}$ the Bambra et al intervention framework sets out how different levels of interventions, different approaches to conceptualising health inequalities and different intervention strategies can combine to reduce health inequalities.

Using this framework (which itself draws on the matrix developed by Dahlgren and Whitehead ${ }^{38}$ ), four levels of intervention are identified: the structural and macropolicy level (the macroeconomic, cultural and environmental context that influences the living standards of the whole population), the public policy level (policies that influence the environments in which people live, work or study), the social networks and community level (the collective actions that affect the health of communities and local areas by building social cohesion and mutual support), and the individual or household level (the interventions and strategies targeting the health individual people or households). Following Bambra et $a l \mathrm{~s}$ characterisation of different intervention approaches to health inequalities (drawing on the typologies developed by Graham and Kelly ${ }^{37}$ and Graham, ${ }^{39}$ ), our framework identifies three conceptual intervention approaches to reducing health inequalities within populations and three equity objectives for these interventions. As such, this framework identifies targeted approaches (directed at on specific groups, ie, deprived, vulnerable or disadvantaged groups-in a population), universal approaches (interventions that apply uniformly to the population) or proportionate universalism (interventions that are applied universally but that their intensity and scale should be proportionate to the level of disadvantage or health gradient across that population) ${ }^{40}$ as the three conceptual approaches to reducing health inequalities within populations. The three equity objectives of these interventions used in this framework follow the definitions from Graham's typology ${ }^{39}$ : 'remedying health disadvantages', which addresses the health needs of the most deprived or disadvantaged population; 'narrowing health gaps', which focuses on reducing the difference in health found between the most privileged and the most disadvantaged groups and 'reducing health gradients', which aims to reduce health differences across the whole population.

Finally, this framework is further augmented with WHO Regional office for Europe's (WHO EURO) definition of essential public health operations ${ }^{41}$ which identifies three core public health functions or services relevant to this work: promoting child health, protecting children from infectious diseases and preventing such diseases. Although WHO EURO recognises that certain actions may be overlapping between these three different public health functions, it broadly defines these as follows. Health promotion refers to intersectoral and interdisciplinary operations enabling people to stay healthy or improve their health and its determinants. Health protection refers to actions primarily involving the use of legal, regulatory or enforcement mechanisms to safeguard public health. Finally, prevention refers to public health services within the health system that target individuals or populations at risk of developing a diseases. ${ }^{41}$

Applied to child health, each intervention could be categorised and analysed according to the framework below (figure 1), in order to identify structures or patterns of interventions related to specific population or health inequalities outcomes.

\section{Scope}

Research questions

- Which public health interventions are effective in reducing morbidity and mortality from infectious diseases among children in LMICs?

- What are the effects-if any-of these interventions on health inequalities?

The Population, Intervention, Comparison/control, Outcomes and Study design (PICOS) for our review are described below:

\section{Population}

The populations of interest are children under 5 years old or households with at least one child under 5 years old, living in countries that have been listed as low-income, lower-middle or upper-middle-income by the World Bank at least once from 2000 to present. ${ }^{42}$ This definition of lowincome, lower-middle or upper middle-income countries will allow us to capture the increased efforts in improving child health further to the adoption of the Millennium Development Goals (MDGs), which was associated to a global under 5 mortality rate dropping by $44 \%$ between 2000 and $2015 .^{9}$

\section{Intervention}

The interventions of interest are public health interventions targeting infectious diseases or associated risk factors in children (table 1). Following our definition of 


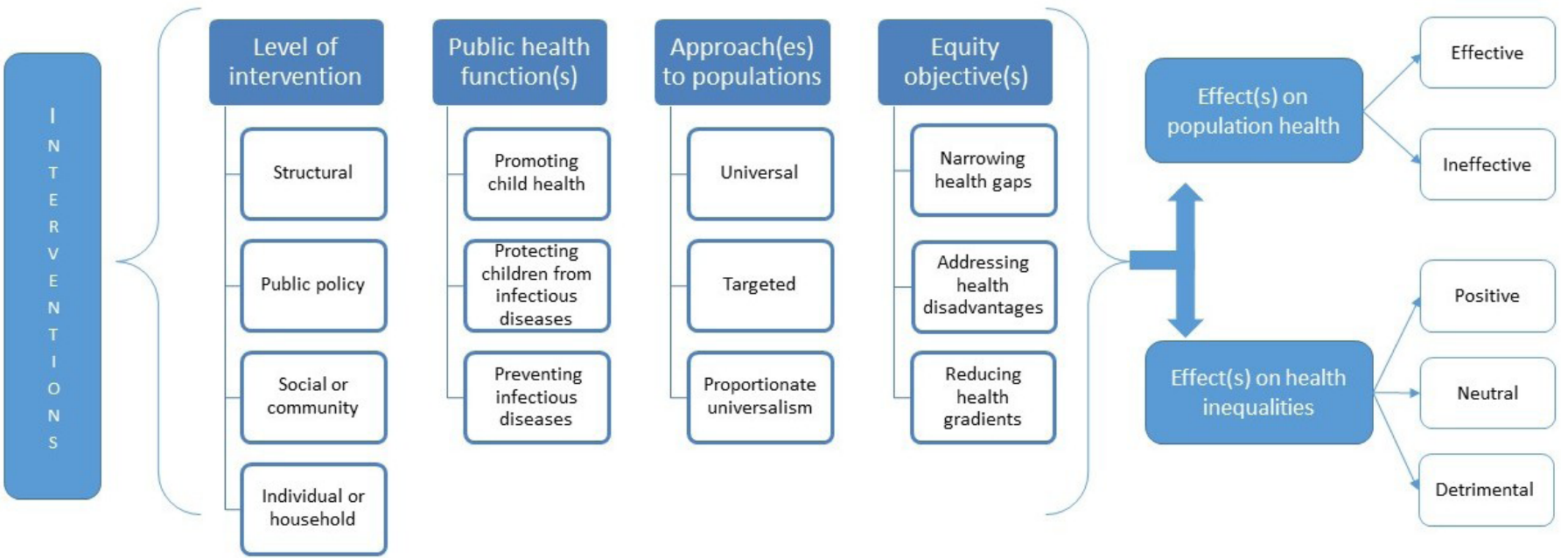

Figure 1 Analytical framework to understand the effect of public health interventions on health inequalities in LMICs. LMICs, low-income and middle-income countries.

public health interventions, these involve active, collective action(s), policy/ies, programme(s) or project(s) aiming at creating change and, ultimately, improving health. These interventions should include primary prevention interventions targeting specific diseases (eg, immunisation programmes or mosquito nets distribution) and policies or interventions addressing environmental, behavioural or metabolic/nutritional risks (eg, support to breastfeeding), as well as protective factors for infectious diseases (eg, cookstove intervention programmes or water and sanitation systems). These interventions may also include wider health promotion or health protection actions that have had an effect on the burden of infectious diseases in children (eg, environmental regulations, parenting programmes or conditional cash transfers, inclusion of preventive services in Universal Coverage packages).

Secondary prevention activities (early detection of a disease before it becomes symptomatic) and tertiary prevention activities (involving improving treatment and recovery, improving the health outcomes in those already affected by a disease) $)^{43}$ as well as curative approaches are beyond the scope of this umbrella review and will be excluded.

Table 1 presents broad types of interventions for which systematic reviews reporting population health impacts have been identified in the Campbell Collaboration and UNICEF Office of Research-Innocenti evidence mega-map on child welfare ${ }^{21}$ and/or that have been identified by professionals and researchers contacted by the review team. These interventions have been categorised according to WHO EURO's definitions of health promotion, protection and prevention. ${ }^{41}$

\section{Comparison/control}

To account for the diversity of methods used to asses public health interventions ${ }^{44}$ and in line with the umbrella review of public health interventions by Thomson $e t a l^{20}$ this umbrella review will consider systematic reviews and evidence synthesis of primary studies with and without control groups. Control groups may include randomised or matched designs. Other comparison groups will also be considered, such as preintervention and postintervention or alternative intervention comparisons.

\section{Outcomes}

The outcomes of interest involve both health and health inequality outcomes in and between populations, which reflect the effectiveness of the intervention. Primary outcomes include population-level measures such as: mortality and morbidity measures for infectious diseases, the number of cases reported for individual infectious diseases, the number of cases averted, the number of deaths due to these diseases, the incidence of these diseases, service uptake or intervention coverage (eg, immunisation, children sleeping under mosquito nets or coverage of postpartum prevention of mother-to-child transmission of HIV).

Secondary outcomes include measures of variation in these health outcomes between groups or populations according to the Progress+factors (table 2).

\section{Study design}

Only systematic reviews (including meta-analysis) and evidence syntheses covering at least two relevant primary studies and published in the last 5 years (2014-2019) will be included. However, no publication date thresholds will be applied to the studies included in individual reviews. This approach will ensure that the review captures the most up-to-date findings while limiting the risk of overlaps and redundancies between reviews. At the same time, applying no publication date limitations to the studies included by individual reviews will allow us to capture the progress made in individual fields of public health, including those achieved during the MDG era.

Systematic reviews involve a systematic search, appraisal and synthesis of research evidence following a transparent and systematic method. ${ }^{24}$ Meta-analyses are a statistical 
Table 1 Types of public health interventions targeting infectious diseases or associated risk factors in children identified in previous research

\begin{tabular}{|c|c|c|c|}
\hline & $\begin{array}{l}\text { Intersectoral and interdisciplinary } \\
\text { operations enabling people to stay } \\
\text { healthy or improve their health } \\
\text { and its determinants }\end{array}$ & $\begin{array}{l}\text { Use of legal, regulatory or } \\
\text { enforcement mechanisms to } \\
\text { safeguard public health }\end{array}$ & $\begin{array}{l}\text { Public health services } \\
\text { within the health system } \\
\text { that target individuals } \\
\text { or populations at risk of } \\
\text { developing a disease }\end{array}$ \\
\hline Public policy level & $\begin{array}{l}\text { Universal health coverage policies } \\
\text { (as applied to children and their } \\
\text { families). } \\
\text { Family policy. } \\
\text { Financial assistance/public } \\
\text { assistance (eg, conditional cash } \\
\text { transfer). } \\
\text { Food policy. } \\
\text { Access to health services } \\
\text { policies. }\end{array}$ & $\begin{array}{l}\text { Environmental health } \\
\text { standard application and } \\
\text { enforcement. }\end{array}$ & $\begin{array}{l}\text { Water, sanitation and } \\
\text { waste management } \\
\text { infrastructure. } \\
\text { Child immunisation } \\
\text { policies and } \\
\text { programmes. }\end{array}$ \\
\hline Social or community level & $\begin{array}{l}\text { Health and nutrition education } \\
\text { Food fortification and } \\
\text { supplements }\end{array}$ & $\begin{array}{l}\text { Pollution and chemical } \\
\text { exposure reduction } \\
\text { interventions (eg, } \\
\text { cookstove distribution). }\end{array}$ & $\begin{array}{l}\text { Hygiene promotion } \\
\text { Parenting programmes } \\
\text { Community outreach } \\
\text { Community health } \\
\text { services } \\
\text { Vector control campaign } \\
\text { (mosquito nets } \\
\text { distribution, insecticide) } \\
\text { Deworming campaigns }\end{array}$ \\
\hline
\end{tabular}

technique used in certain systematic reviews in order to combine the results of quantitative studies. ${ }^{24}$ Evidence syntheses bring individual studies within the context of global knowledge for a given topic. They use a transparent methodology detailing a clear question and the method to identify, select, appraise, analyse and synthesise studies. ${ }^{45}$ Following these definitions (and in keeping with the criteria of the Database of Abstracts of Reviews of Effects), ${ }^{46}$ three key elements will be required for systematic reviews or evidence syntheses to be included in this umbrella review: (1) a clear question, (2) a transparent method for the search, selection and appraisal of evidence or studies and (3) a separate synthesis of the results or evidence meeting this umbrella review's scope and inclusion criteria.
In keeping with other public health umbrella reviews, ${ }^{20}$ the types of primary studies included within the systematic reviews may consist of experimental or quasiexperimental studies, with or without control groups, such as: randomised and non-randomised controlled trials, controlled observational studies, before and after studies, interrupted time-series studies, natural policy experiments, evaluation studies, cohort studies, casecontrol studies and ecological studies.

\section{Search strategy}

The literature search was undertaken between 19 and 30 June 2019 using the following databases: the Cochrane Library (includes the Cochrane Database of Systematic Reviews, the Cochrane Central Register of Controlled 
Table 2 Factors contributing to health (in)equity (known as progress+factors)

\begin{tabular}{ll}
\hline Place of residence & Rural/urban, housing characteristics \\
\hline $\begin{array}{l}\text { Race, ethnicity, cultural } \\
\text { background }\end{array}$ & Racial, ethnic and sociocultural background \\
$\begin{array}{l}\text { Occupation } \\
\text { Gender and sex }\end{array}$ & Employment status, type of occupation, employment-based benefits. \\
\hline Religion & Religious background \\
\hline Education & Years in and/or level of education attained, school type \\
\hline Social capital & $\begin{array}{l}\text { Social relationships and networks, support and participation at neighbourhood/community/ } \\
\text { family level }\end{array}$ \\
\hline Socioeconomic status & Income, welfare, assets and resources at individual or household level \\
+ & These include other factors of inequalities such as \\
& age, disability, being part of a vulnerable group (eg, refugee or displaced person, minority) \\
\hline
\end{tabular}

Adapted from Kavanagh et a/ ${ }^{50}$; O'Neill et al. ${ }^{51}$

Trials and the Cochrane Clinical Answers), Medline (Ovid), EMBASE (Ovid), the CAB Global Health database (Ovid), Health Evidence (McMaster University), the Campbell Collaboration Library of Systematic Reviews (The Campbell Library), International Initiative for Impact Evaluation Systematic review repository (International Initiative for Impact Evaluation-3ie), Scopus (Scopus), the Social Sciences Citation Index (SSCI, Web of Science) and PROSPERO (Centre for Reviews and Dissemination, University of York). Additionally, a manual search will be performed in Google Scholar and on the following websites:

- UNICEF Office of Research-Innocenti https://www. unicef-irc.org/publications/

- UNICEF https://www.unicef.org/publications/ and https://data.unicef.org/resources/

- WHO https://apps.who.int/iris/ and https://www. who.int/maternal_child_adolescent/

The search was performed by one reviewer (EB), with guidance from the research librarians (MRJ and AK) regarding the databases chosen and the design of the search strings. The search string used a combination of $\mathrm{MeSH}$ terms and free-text keywords and was adapted by one reviewer (EB) for each database. Prior to developing the full search (online supplementary annex 1), test search strings have been piloted by one reviewer (EB) with comments and advice from a second reviewer (KT) and the research librarians (MRJ and AK). Once the search string has been defined, the Polyglot Search Syntax Translator ${ }^{47}$ was used by one reviewer (EB) to facilitate and support the translation of the search strings from one database to the other. Searches were limited to records published since 2000. No restriction of language was applied. The full-search strategy can be found in online supplementary annex 2.

\section{Screening}

Article screening will be carried out the software Rayyan. ${ }^{48}$ Titles and abstracts will be screened by one reviewer (EB) according to the inclusion/exclusion criteria listed below. Ten per cent of the titles and abstracts selected at random will be screened independently by a second reviewer (KT). Screening and inclusion of full texts will then be assessed independently by two reviewers (TM and $\mathrm{EB}$ or DS and EB). An inter-rater reliability will be assessed using the kappa statistic at each screening stage. Discrepancies will be resolved by consensus between the two reviewers. If a consensus fails to be reached, the relevant record will be sent to the third reviewer for arbitration. A flow chart describing the study selection process will be developed using the Preferred Reporting Items for Systematic Reviews and Meta-Analyses (PRISMA) guidelines. $^{49}$

\section{Study selection}

Inclusion/exclusion criteria

Inclusion

1. The review team has access to the publication's full text.

2. The publication was published between 2014 and 2019 .

3. The publication is an academic article or a report of a systematic review (including a meta-analysis) or an evidence synthesis as defined in PICOS, synthesising at least two relevant primary studies.

4. The publication covers exclusively or synthesises separately, studies in countries defined at least once since 2000 as low-income, lower-middle or upper-middleincome by the World Bank historical classification. ${ }^{42}$

5. The publication covers interventions targeting children from live birth until 5 years old or households with children under 5 years old.

6. The publication covers active, collective health promotion, health protection or primary prevention public health interventions addressing or affecting the burden of infectious diseases or their risk factors.

7. The publication reports health or health inequalities outcomes in and between populations, disaggregated by one or more of the PROGRESS+factors as defined in PICOS. 


\section{Exclusion}

1. The publication's full text cannot be obtained by the review team.

2. The publication was published before 2014 .

3. The publication is a primary study, a conference proceeding or paper, an abstract, editorial, letter, comment, erratum, survey, note or a doctoral thesis; or does not meet one or more of the three key elements of systematic reviews and evidence syntheses as defined in PICOS; or does not synthesise at least 2 relevant primary studies.

4. The publication only includes interventions in country/ies the World Bank historical classification has continuously defined as high-income between 2000 and $2019,{ }^{42}$ or does not synthesise or report on low-income, lower-middle or upper-middle-income countries separately.

5. The publication only includes interventions targeting adults, pregnant women, adolescents or children older than 5 years old; or fail to synthesise primary studies' results for the under 5 age group separately.

6. The publication only includes curative interventions or secondary or tertiary prevention interventions, is not addressing or affecting the burden of infectious diseases or their risk factors, or only report trends in individual behaviours without any actions aiming at changing or influencing them.

7. The publication does not include a relevant overall health outcome or disaggregated information by or between population groups.

\section{Data extraction}

Within the reviewer team (TM and EB; DS and EB or $\mathrm{EB}$ and KT), data will be extracted by one reviewer and checked by a second. A data extraction form will be developed using the PROGRESS+framework ${ }^{5051}$ and the PRISMA-E checklist. ${ }^{52}$ This form will include studies' details; the characteristics of interventions covered according to our framework; the PROGRESS+factors covered (if any); their main findings and outcomes at population level and/or disaggregated by relevant groups as well as critical assessment criteria (see online supplementary annex 3). Discrepancies will be resolved by consensus between the two reviewers. If a consensus fails to be reached, the relevant record will be sent to a third reviewer for arbitration.

\section{Quality appraisal}

Within the reviewer team (TM and EB; DS and EB or EB and KT), the critical appraisal will be carried out by one reviewer using AMSTAR $2^{53}$ at the same time as the data extraction, and checked by a second reviewer. Discrepancies will be resolved by consensus between the two reviewers. If a consensus fails to be reached, the relevant record will be sent to a third reviewer for arbitration.

\section{Overlaps between studies}

As they extract relevant information, the reviewers (EB, DS and TM) will catalogue the primary studies covered by individual review into a citation matrix developed by Thomson et $a l^{28}$ in order to identify overlaps (online supplementary annex 3 ). This citation list will be checked by a second reviewer alongside the critical appraisal and extraction sheet.

\section{Patient and public involvement \\ No patient involved.}

The scope of this review was informed by the literature and discussions with public health experts.

\section{SYNTHESIS}

The findings of the publication included will be collated using a narrative synthesis approach. Indeed, the broad scope of interventions, study designs and type of outcomes included in public health umbrella reviews make narrative synthesis approaches more suitable than quantitative analysis. ${ }^{26}$ Findings from individual reviews or syntheses will be categorised according to the framework defined previously in order to identify structures or patterns of interventions related to specific population or health inequalities outcomes. Then, for each category or pattern, these findings will be analysed according to their effect on population health outcomes and health inequalities, highlighting similarities and differences for various types of interventions and the strength of the evidence. To allow us to identify potential gaps in the research affecting a specific field or type of interventions, reviews failing to report health inequalities will be marked and analysed separately. The citation matrix developed during the extraction will also allow for the identification of overlaps between reviews, which will be analysed according to the reviews' publication date, scope and quality.

A discussion on the main gaps and methodological challenges faced by the review will also be included.

\section{PILOT SEARCH}

The search strategy was piloted in a health database (Medline, via Ovid) and a social science database (Scopus) (see online supplementary annex 1), with support and guidance from NTNU research librarians (MRJ and AK). A selection of four tracer systematic reviews and evidence syntheses ${ }^{54-57}$ was used to test whether the different search strings identified them. The choice of the final search string was made based on the result of each stage (online supplementary annex 4).

At a first stage, search terms included the population, the intervention, the type of study covered using either the database own limit options or the terminology developed by the Scottish Intercollegiate Guidelines Network ${ }^{58}$ and the publication year. These strings returned 3091 records in Medline and 4148 in Scopus (as of 22 May 2019).

At the second stage, terminology related to the primary outcomes (health outcomes at population level) was added. As the review covers both population health and health inequalities outcomes, it was decided not to include 
health inequality terms in order not to lose reviews not explicitly reporting health inequalities outcomes. These strings returned 2404 records in Medline and 3572 in Scopus (as of 22 May 2019).

The pilot shows a small reduction of the number of records found between the two phases by $14 \%$ in Scopus and 23\% in Medline while keeping all four test articles. Therefore, it was decided to use the search string from the second pilot for this search. The search string was translated from Medline onto the other six databases (see online supplementary annex 2). The Polyglot Search Syntax Translator ${ }^{47}$ was used to facilitate and support the translation of the search strings from one database to the other.

\section{DISCUSSION}

Although progress has been made in reducing the burden of infectious diseases during the MDG era, ${ }^{37}$ the burden among children under the age of 5 remains significant in LMICs, with stark inequalities between social groups. Infectious diseases are still among the leading causes of deaths and among under $5 .{ }^{611}$ Mortality data collected during the MDGs also confirm that children from disadvantaged households and neighbourhoods were more likely to die before the age of 5 than their counterparts born in more privileged groups. ${ }^{59}$

By their multisectoral nature, public health interventions offer great opportunities to support the efforts towards achieving the UN Sustainable Development Goals as a whole and the targets related to child health and health inequalities in particular. Yet, current projections show great variations between countries' probability to achieve these goals, ${ }^{60}$ calling for increased efforts locally and globally in the next decade to improve child health equitably.

This umbrella review will help to assess the availability and quality of evidence on the population health and equity effect of selected public health interventions addressing the burden of infectious diseases in children in LMICs. It will identify interventions that have had a proven impact on the protection of child health via the prevention of infectious diseases and inequalities within them. Finally, it will help to identify areas or sectors where the evidence on equity is weak and needs further research.

\section{Strengths and limitations}

This umbrella review will search for a wide range of public health interventions, thus offering a good mapping of the field and the state of evidence about equity. Additionally, including both academic and grey literature as well as different approaches and definitions of equity will help overcome some of difficulties related to the sources of information or the search for equity-related studies, which previous mapping of the literature on this topic faced.

However, the wide scope of this review also constrains the type of synthesis and analysis possible with the data extracted, hence our decision to opt for a narrative synthesis rather than a quantitative analysis. It should also be noted that more recent primary studies on new interventions may not be captured by the review, as they may not have been synthesised into reviews yet. Yet, the scope and design of this review will ensure a solid assessment the availability and quality of evidence on this issue, thus offering a solid evidence base for future research as well as public health practice and policy in LMICs.

\section{DISSEMINATION}

The protocol for this review has been registered with PROSPERO (CRD42019141673).

The results of the review will be submitted for publication in academic journals and presented at international public health conferences. Additionally, key findings will be summarised for dissemination to a wider policy and general public audience as part of the Centre for Global Health Inequalities Research's policy work.

\section{Author affiliations}

${ }^{1}$ Centre for Global Health Inequalities Research (CHAIN) / Department of Sociology and Political Science, NTNU, Trondheim, Norway

${ }^{2}$ Institute of Health and Society, Newcastle University, Newcastle upon Tyne, UK ${ }^{3}$ Department of Public Health and Nursing / CHAIN, NTNU, Trondheim, Norway ${ }^{4}$ Department of Anthropology, Durham University, Stockton-on-Tees, UK

${ }^{5}$ School of Pharmacy / CHAIN, Newcastle University, Newcastle upon Tyne, UK ${ }^{6}$ Dragvoll library, NTNU, Trondheim, Norway

${ }^{7}$ Medicine and Health Library, NTNU, Trondheim, Norway

${ }^{8}$ Institute of Health \& Society / CHAIN, Newcastle University, Newcastle upon Tyne, UK

\section{Twitter Adam Todd @adam.todd138}

Contributors EB led the drafting and revising of the manuscript. KT, CB, AT and NA provided key input on the scope and design of the review. KT, MRJ and AK provided advice, support and comments on the search strategy and the pilot, with MRJ reviewing pilot search strings prior to the final search. TM, DS, KT, CB, AT and NA contributed to the writing and revision of the manuscript. All authors read and approved the final manuscript.

Funding The authors have not declared a specific grant for this research from any funding agency in the public, commercial or not-for-profit sectors.

Competing interests None declared.

Patient consent for publication Not required.

Ethics approval This review will exclusively work with anonymous group-level information available from published reviews. As a result, there is no risk to identifying individual data or disclosing confidential information. Thus, this study did not require seeking ethical approval.

Provenance and peer review Not commissioned; externally peer reviewed.

Open access This is an open access article distributed in accordance with the Creative Commons Attribution Non Commercial (CC BY-NC 4.0) license, which permits others to distribute, remix, adapt, build upon this work non-commercially, and license their derivative works on different terms, provided the original work is properly cited, appropriate credit is given, any changes made indicated, and the use is non-commercial. See: http://creativecommons.org/licenses/by-nc/4.0/.

\section{ORCID iDs}

Elodie Besnier http://orcid.org/0000-0003-2981-7455

Katie Thomson https://orcid.org/0000-0002-9614-728X

Nasima Akhter https://orcid.org/0000-0002-5424-1593

Adam Todd http://orcid.org/0000-0003-1496-9341

Magnus Rom Jensen http://orcid.org/0000-0002-1810-2676

Clare Bambra https://orcid.org/0000-0002-1294-6851 


\section{REFERENCES}

1 The Lancet. Life, death, and disability in 2016. Lancet 2017;390:1083.

2 Wang $\mathrm{H}$, Abajobir AA, Abate $\mathrm{KH}$, et al. Global, regional, and national under-5 mortality, adult mortality, age-specific mortality, and life expectancy, 1970-2016: a systematic analysis for the global burden of disease study 2016. The Lancet 2017;390:1084-150.

3 Watkins K. A fair chance for every child. New York, NY: UNICEF, 2016. https://www.unicef.org/publications/index 91711.html

4 Wilkinson R. Ourselves and others - for better or worse: social vulnerability and inequality. In: Marmot M, Wilkinson R, eds. Social determinants of health. Oxford, New York: Oxford University Press, 2005. https://global.oup.com/academic/product/ social-determinants-of-health-9780198565895?q=Social\% 20Determinants\%20of\%20Health\%20wilkinson\%20marmot\% 202nd\%20ed\&lang=en\&cc $=$ no

5 Barros FC, Victora CG, Scherpbier RW. Health and nutrition of children: equity and social determinants. In: Blas E, Kurup AS, eds. Equity, social determinants and public health programmes. World Health Organization, 2010: 49-76.

6 Global Burden of Disease Collaborative Network. Global burden of disease study 2017 (GBD 2017) results. Seattle, United States: Institute for Health Metrics and Evaluation (IHME), 2018. http://ghdx. healthdata.org/gbd-results-tool

$7 \mathrm{Kyu} \mathrm{HH}$, Abate D, Abate $\mathrm{KH}$, et al. Global, regional, and national disability-adjusted life-years (DALYs) for 359 diseases and injuries and healthy life expectancy (HALE) for 195 countries and territories, 1990-2017: a systematic analysis for the global burden of disease study 2017. Lancet 2018;392:1859-922.

8 Roth GA, Abate D, Abate KH, et al. Global, regional, and national age-sex-specific mortality for 282 causes of death in 195 countries and territories, 1980-2017: a systematic analysis for the global burden of disease study 2017. Lancet 2018;392:1736-88.

9 UNDESA. The sustainable development goals report 2017. New York: United Nations, 2017. https://unstats.un.org/sdgs/report/2017/

10 Institute for Health Metrics and Evaluation (IHME). GBD compare data visualization, 2018. Available: http://vizhub.healthdata.org/gbdcompare [Accessed 12 Jul 2018].

11 WHO. World health statistics 2018: monitoring health for the SDGs. Geneva: WHO, 2018. https://www.who.int/gho/publications/world_ health_statistics/2018/en/

12 WHO. Global vaccine action plan 2011-2020. Geneva: WHO, 2013. http://www.who.int/immunization/global_vaccine_action_plan/GVAP doc_2011_2020/en/

$13 \mathrm{WHO}$. Table 2: Summary of WHO Position Papers - Recommended Routine Immunizations for Children, 2018. Available: http://www. who.int/immunization/policy/Immunization_routine_table2.pdf?ua=1 [Accessed 1 Aug 2018].

14 Lassi ZS, Mallick D, Das JK, et al. Essential interventions for child health. Reprod Health 2014;11:S4.

15 Victora CG, Wagstaff A, Schellenberg JA, et al. Applying an equity lens to child health and mortality: more of the same is not enough. Lancet 2003;362:233-41.

16 Commission on Social Determinants of Health. Closing the gap in a generation: health equity through action on the social determinants of health. Backgrounders - key concepts. Geneva: World Health Organization, 2008. http://www.who.int/social_determinants/ thecommission/finalreport/key_concepts/en/

17 Bosch-Capblanch X, Zuske M-K, Auer C. Research on subgroups is not research on equity attributes: evidence from an overview of systematic reviews on vaccination. Int J Equity Health 2017;16:95.

18 Hillier-Brown FC, Bambra CL, Cairns J-M, et al. A systematic review of the effectiveness of individual, community and societal level interventions at reducing socioeconomic inequalities in obesity amongst children. BMC Public Health 2014;14:834.

19 Blas E, Kurup AS. Equity, social determinants and public health programmes. World Health Organization, 2010.

20 Thomson K, Hillier-Brown F, Todd A, et al. The effects of public health policies on health inequalities in high-income countries: an umbrella review. BMC Public Health 2018;18.

21 Campbell Collaboration,. Unicef office of Research- Innocenti. child welfare Mega map. Campbell Collab, 2018. Available: https://camp bellcollaboration.org/better-evidence/evidence-gap-maps/childwelfare-mega-map.html [Accessed 20 Jul 2018].

22 White H, Saran A, Kanojia Y. Goal area 5: every child has an equitable chance in life. Innocenti Res brief 2018, 2018. Available: https://campbellcollaboration.org/images/pdf/Campbell-UNICEFIRB-SG5.pdf [Accessed 14 Jun 2019].

23 Welch V, Tugwell P, Petticrew M, et al. How effects on health equity are assessed in systematic reviews of interventions. Cochrane Database Syst Rev 2010:MR000028.
24 Grant MJ, Booth A. A typology of reviews: an analysis of 14 review types and associated methodologies. Health Inf Libr J 2009;26:91-108.

25 Becker LA, Oxman AD. Overviews of reviews. In: Higgins JPT, Green $\mathrm{S}$, eds. Cochrane handbook for systematic reviews of interventions. Chichester, England; Hoboken, NJ: Wiley-Blackwell, 2008.

26 Bambra C, Gibson M, Sowden A, et al. Tackling the wider social determinants of health and health inequalities: evidence from systematic reviews. J Epidemiol Community Health 2010;64:284-91.

27 Bambra C, Gibson M. Case study of public health. In: BiondiZoccai G, ed. Umbrella reviews: evidence synthesis with Overviews of reviews and Meta-Epidemiologic studies. Cham: Springer International Publishing, 2016: 343-62.

28 Thomson K, Hillier-Brown F, Walton N, et al. The effects of community pharmacy-delivered public health interventions on population health and health inequalities: a review of reviews. Prev Med 2019;124:98-109.

29 Hillier-Brown F, Thomson K, Mcgowan V, et al. The effects of social protection policies on health inequalities: evidence from systematic reviews. Scand J Public Health 2019;47:655-65.

30 McMahon N, Thomson K, Kaner E, et al. Effects of prevention and harm reduction interventions on gambling behaviours and gambling related harm: an umbrella review. Addict Behav 2019;90:380-8.

31 World Health Organization. International statistical classification of diseases and related health problems (11th revision. Geneva: WHO, 2018. https://icd.who.int/browse11/l-m/en

32 Krieger N. Epidemiology and the people's health: theory and context. Oxford: Oxford University Press, 2011.

33 Acheson D. Public health in England: the report of the Committee of inquiry into the future development of the public health function London: HMSO, 1988.

34 Hawe P, Potvin L. What is population health intervention research? Can J Public Health 2009;100:18-14.

35 Bambra CL, Hillier FC, Cairns J-M, et al. How effective are interventions at reducing socioeconomic inequalities in obesity among children and adults? Two systematic reviews. Public Health Res 2015;3:1-446.

36 Whitehead M. A typology of actions to tackle social inequalities in health. J Epidemiol Community Health 2007;61:473-8.

37 Graham H, Kelly MP. Health inequalities: concepts, frameworks and policy. London: Health Development Agency, 2004. file:///C:/Users/ elodieb/Downloads/Health_Inequalities_Concepts_Frameworks_and Policy.pdf

38 Dahlgren G, Whitehead M. Policies and strategies to promote social equity in health background document to who - strategy paper for Europe. Stockholm, Sweden: Institute for Futures Studies, 1991.

39 Graham H. Tackling inequalities in health in England: remedying health disadvantages, narrowing health gaps or reducing health gradients? J Soc Policy 2004;33:115-31.

40 Marmot M, Allen J, Goldblatt P, et al. Fair Society, healthy lives: the Marmot review. London: UCL Institute of Health Equity, 2010. http:// www.instituteofhealthequity.org/resources-reports/fair-societyhealthy-lives-the-marmot-review/

41 WHO EURO. Self-Assessment tool for the evaluation of essential public health operations in the who European region. Copenhagen: WHO Regional Office for Europe, 2015. http://www.euro.who. int/en/health-topics/Health-systems/public-health-services/ publications/2015/self-assessment-tool-for-the-evaluation-ofessential-public-health-operations-in-the-who-european-region2015

42 The World Bank. World bank country and lending groups, 2019. Available: https://datahelpdesk.worldbank.org/knowledgebase/ articles/906519-world-bank-country-and-lending-groups [Accessed 1 Mar 2019].

43 WHO EURO. EPHO5: disease prevention, including early detection of illness. World health organ. reg. off. Eur, 2018. Available: http:// www.euro.who.int/en/health-topics/Health-systems/public-healthservices/policy/the-10-essential-public-health-operations/epho5disease-prevention,-including-early-detection-of-illness2 [Accessed 29 Oct 2018].

44 Petticrew M, Roberts H. Evidence, hierarchies, and typologies: horses for courses. J Epidemiol Community Health 2003;57:527-9.

45 What is evidence synthesis? 2015. Available: https:// evidencesynthesis.org/what-is-evidence-synthesis/ [Accessed 29 Oct 2018].

46 NHS Centre for Reviews and Dissemination. Database of Abstracts of reviews of effects (Dare), 2002. Available: https://www.crd.york.ac. uk/CRDWeb/AboutPage.asp [Accessed 17 Jun 2019]. 
47 Centre for Evidence-Based Practice, Bond University. Polyglot search Translator. Syst. rev. Accel. Available: http://crebp-sra.com/\#/ polyglot [Accessed 14 May 2019].

48 Ouzzani M, Hammady H, Fedorowicz Z, et al. Rayyan-a web and mobile APP for systematic reviews. Syst Rev 2016;5.

49 Moher D, Liberati A, Tetzlaff J, et al. Preferred reporting items for systematic reviews and meta-analyses: the PRISMA statement. PLoS Med 2009;6:e1000097.

50 Kavanagh J, Oliver S, Lorenc T. Reflections on developing and using PROGRESSPlus. Equity Update 2008;2:1-3.

51 O'Neill J, Tabish H, Welch V, et al. Applying an equity lens to interventions: using progress ensures consideration of socially stratifying factors to illuminate inequities in health. J Clin Epidemiol 2014;67:56-64.

52 Welch V, Petticrew M, Tugwell P, et al. PRISMA-Equity 2012 extension: reporting guidelines for systematic reviews with a focus on health equity. PLoS Med 2012;9:e1001333.

53 Shea BJ, Reeves BC, Wells G, et al. AMSTAR 2: a critical appraisal tool for systematic reviews that include randomised or nonrandomised studies of healthcare interventions, or both. BMJ 2017;358:j4008.

54 Crocker-Buque T, Mindra G, Duncan R, et al. Immunization, urbanization and slums - a systematic review of factors and interventions. BMC Public Health 2017; 17:556.
55 Gilmore B, McAuliffe E. Effectiveness of community health workers delivering preventive interventions for maternal and child health in low- and middle-income countries: a systematic review. BMC Public Health 2013;13:847.

56 Owusu-Addo E, Cross R. The impact of conditional cash transfers on child health in low- and middle-income countries: a systematic review. Int J Public Health 2014;59:609-18.

57 Yuan B, Målqvist M, Trygg N, et al. What interventions are effective on reducing inequalities in maternal and child health in low- and middle-income settings? A systematic review. BMC Public Health 2014; 14:634.

58 Scottish Inter-collegiate Guide-lines Network (SIGN). Search filters, 2015. Available: https://www.sign.ac.uk/search-filters.html [Accessed 17 Aug 2018].

59 UNDESA. The millennium development goals report 2015. New York: United Nations Secretariat, 2015. http://www.un.org/en/ development/desa/publications/mdg-report-2015.html

60 Lozano R, Fullman N, Abate D, et al. Measuring progress from 1990 to 2017 and projecting attainment to 2030 of the health-related sustainable development goals for 195 countries and territories: a systematic analysis for the global burden of disease study 2017. Lancet 2018;392:2091-138. 